\title{
Oral corticosteroid dose changes and impact on peripheral blood eosinophil counts in patients with severe eosinophilic asthma: a post hoc analysis
}

Charlene M. Prazma ${ }^{1 *}$, Elisabeth H. Bel ${ }^{2}$, Robert G. Price ${ }^{3}$, Eric S. Bradford ${ }^{4}$, Frank C. Albers ${ }^{1}$ and Steven W. Yancey ${ }^{4}$

\begin{abstract}
Background: An inverse relationship between oral corticosteroid (OCS) dose and peripheral blood eosinophil (PBE) count is widely recognized in patients with severe eosinophilic asthma; however, there are limited data available to quantify this relationship. This post hoc analysis of the SIRIUS study (NCT01691508) examined the impact of weekly incremental OCS dose reductions on PBE counts during the 3-8-week optimization phase of the study.

Methods: SIRIUS was a randomized, double-blind study involving patients with severe asthma ( $\geq 12$ years old), which included an initial OCS dose optimization phase prior to randomization. Regression analysis assuming a linear relationship between change in OCS dose and change in log (PBE count) during the optimization phase was used to estimate the changes in PBE count following specific decreases in OCS dose.

Results: All 135 patients from the SIRIUS intent-to-treat population were included in this analysis. During the optimization period, 44\% (60/135) of patients reduced their OCS dose, with an increase in geometric mean PBE count

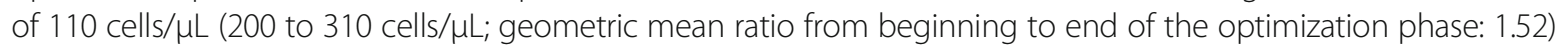
recorded in these patients. The model estimated that reduction of daily OCS dose by $5 \mathrm{mg} /$ day led to a $41 \%$ increase in PBE count (mean ratio to beginning of optimization phase: 1.41 [95\% confidence interval (Cl); 1.22, 1.63]).

Conclusion: These data confirmed and quantified the inverse association between OCS dose and PBE count. These insights will help to inform clinicians when tapering OCS doses in patients with severe eosinophilic asthma.
\end{abstract}

Keywords: Severe eosinophilic asthma, Peripheral blood eosinophil, Oral corticosteroids

\section{Background}

Eosinophilic airway inflammation, as measured by peripheral blood eosinophil (PBE) count, [1] has been associated with particularly poor symptom control and recurrent exacerbations in a subset of patients with severe asthma. One clinical approach to reduce exacerbations within this patient population is to increase the systemic corticosteroid dose to suppress eosinophilic inflammation. [2] Maintenance oral corticosteroid (OCS) therapy is required in up to $30 \%$ of patients with severe asthma; however, physicians are aware of the potential

\footnotetext{
* Correspondence: charlene.m.prazma@gsk.com

${ }^{1}$ Respiratory Medical Franchise, GSK, Research Triangle Park, 5 Moore Drive,

PO Box 13398, Raleigh-Durham, North Carolina 27709, USA

Full list of author information is available at the end of the article
}

side effects associated with corticosteroid use $[3,4]$ and, where possible, strive to reduce or remove OCS without compromising symptom control.

While OCS have a broad impact on airway inflammatory cell populations, the efficacy of OCS treatment in patients with severe asthma has been primarily attributed to increased apoptosis of eosinophils. [5] It is widely recognized that an inverse relationship exists between OCS dose and PBE count; however, there are limited data available to physicians that quantify this relationship. The SIRIUS study (NCT01691508) assessed the corticosteroid-sparing effect of mepolizumab in patients with severe eosinophilic asthma. [6] The study included an initial optimization phase, which aimed to define the lowest OCS dose required to maintain asthma control prior to randomization.

(c) The Author(s). 2019 Open Access This article is distributed under the terms of the Creative Commons Attribution 4.0 International License (http://creativecommons.org/licenses/by/4.0/), which permits unrestricted use, distribution, and 
This post hoc analysis of SIRIUS, examined the impact of incremental OCS dose reductions on PBE counts during the optimization phase.

\section{Methods}

SIRIUS was a 24-week, multicenter, randomized, placebo-controlled, double-blind, parallel-group study in patients $\geq 12$ years of age diagnosed with severe asthma, with a PBE count $\geq 150$ cells $/ \mu \mathrm{L}$ at screening or $\geq 300$ cells $/ \mu \mathrm{L}$ in the prior 12 months. All patients had a documented requirement for treatment with OCS (5-35 mg/day prednisone or equivalent) and high-dose inhaled corticosteroids for $\geq 6$ months prior to study entry, plus additional controller(s) for $\geq 3$ months; there was no exacerbation history requirement. Patients' asthma control was assessed with the Asthma Control Questionnaire-5 (ACQ-5) at the beginning of the optimization phase (Visit 1), and each subsequent week until randomization. Over the course of the optimization phase (3-8 weeks), patients with controlled or improved asthma status reduced their OCS dose by $5 \mathrm{mg} /$ day each week (if receiving 20-35 mg/day OCS) or $2.5 \mathrm{mg} /$ day each week (if receiving 5-15 mg/day OCS) until they experienced an exacerbation or worsening of asthma control (increase of $\geq 0.5$ points in ACQ-5 score from Visit 1). Following an exacerbation, patients received oral/parenteral corticosteroids at double the current maintenance OCS dose for 3-7 days; thereafter the maintenance OCS dose was increased by one level per the titration schedule. Following worsening of asthma control, patients increased their OCS dose by one level per the titration schedule. All other background medications remained unchanged. In this post hoc analysis we describe the changes over the optimization phase in (1) OCS dose and (2) PBE count in response to OCS dose modification. Additionally, we conducted a regression analysis assuming a linear relationship between change in OCS dose and change in log (PBE count) during the optimization phase. From this model we estimated changes in PBE count following $1 \mathrm{mg} /$ day and $5 \mathrm{mg} /$ day decreases in OCS dose.

\section{Results}

All 135 patients from the SIRIUS intent-to-treat population were included (Additional file 1: Table S1). During the optimization phase, the group median OCS dose decreased from $12.5 \mathrm{mg} /$ day to $10.0 \mathrm{mg} /$ day. In total, 60 (44\%) patients decreased their OCS dose over the optimization period, and experienced a corresponding increase in geometric mean PBE count from 200 to 310 cells $/ \mu \mathrm{L}$ (increase of 110 cells $/ \mu \mathrm{L}$; geometric mean ratio from beginning to end of the optimization phase: 1.52). Conversely, among the 31 (23\%) patients who increased their OCS dose, there was a reduction in geometric mean PBE count from 330 to 200 cells $/ \mu \mathrm{L}$ (decrease of 130 cells $/ \mu \mathrm{L}$; geometric mean ratio: 0.58 ). Forty-four (33\%) patients maintained their OCS dose over the optimization phase (reduction in geometric mean PBE count from 240 to 210 cells $/ \mu \mathrm{L}$; decrease of 30 cells $/ \mu \mathrm{L}$; geometric mean ratio: 0.80 ).

Results from the regression analysis confirmed the inverse relationship observed between change in OCS dose and PBE count (Fig. 1). Based on our model, a $1 \mathrm{mg} /$ day reduction in OCS dose resulted in a $7 \%$ increase in PBE count during the optimization phase (ratio to beginning of the optimization phase: 1.07 [95\% confidence interval: $1.04,1.10])$. Reducing the OCS dose by $5 \mathrm{mg}$ /day resulted in a $41 \%$ increase in PBE count during the optimization phase (ratio to beginning of the optimization phase: 1.41 [95\% confidence interval: 1.22, 1.63]).

\section{Discussion}

As expected, this analysis demonstrated that a reduction in daily OCS dose led to an increase in PBE count, and an increase in OCS dose results in a decrease in PBE count. Overall, the reduction in group median OCS dose over the optimization phase suggests that some patients may be receiving higher OCS doses than required to control their disease symptoms, while others were on a dose too low to confer control. These data highlight the importance of continually monitoring a patient's OCS dose to establish, and in some clinical scenarios, reestablish the minimally effective dose for patients receiving chronic OCS therapy and provides an awareness of the correlation between an OCS dose reduction and the impact on PBE. The frequency of real world PBE measurements should be considered on an individual patient basis as various factors may influence PBE such as the initial maintenance OCS dose, the magnitude of change in OCS dose, and the pace of tapering. Additionally, in clinical trials, OCS dose optimization prior to "on-treatment" OCS reduction, may help to mitigate predictable trial effects resulting in large OCS reductions in the placebo arm related to a portion of patients being maintained on a higher OCS dose than that necessary to maintain asthma control.

An increase in PBE count following OCS dose reduction could be indicative of increasing eosinophilic lung inflammation. Prior corticosteroid reduction studies have consistently demonstrated increasing sputum eosinophil counts to be predictive of the development of an exacerbation. [7, 8] Given that sputum eosinophilia ( $\geq 2 \%$ ) has been shown to correlate to blood eosinophil counts $\geq 150$ cells $/ \mu \mathrm{L}$ in patients with severe asthma, [9] PBE counts $\geq 150$ cells $/ \mu \mathrm{L}$ may also serve as an accessible biomarker for a potential loss of asthma control or future exacerbation.

\section{Conclusion}

Overall, our analysis demonstrated a linear inverse relationship between OCS dose and PBE count, with every 


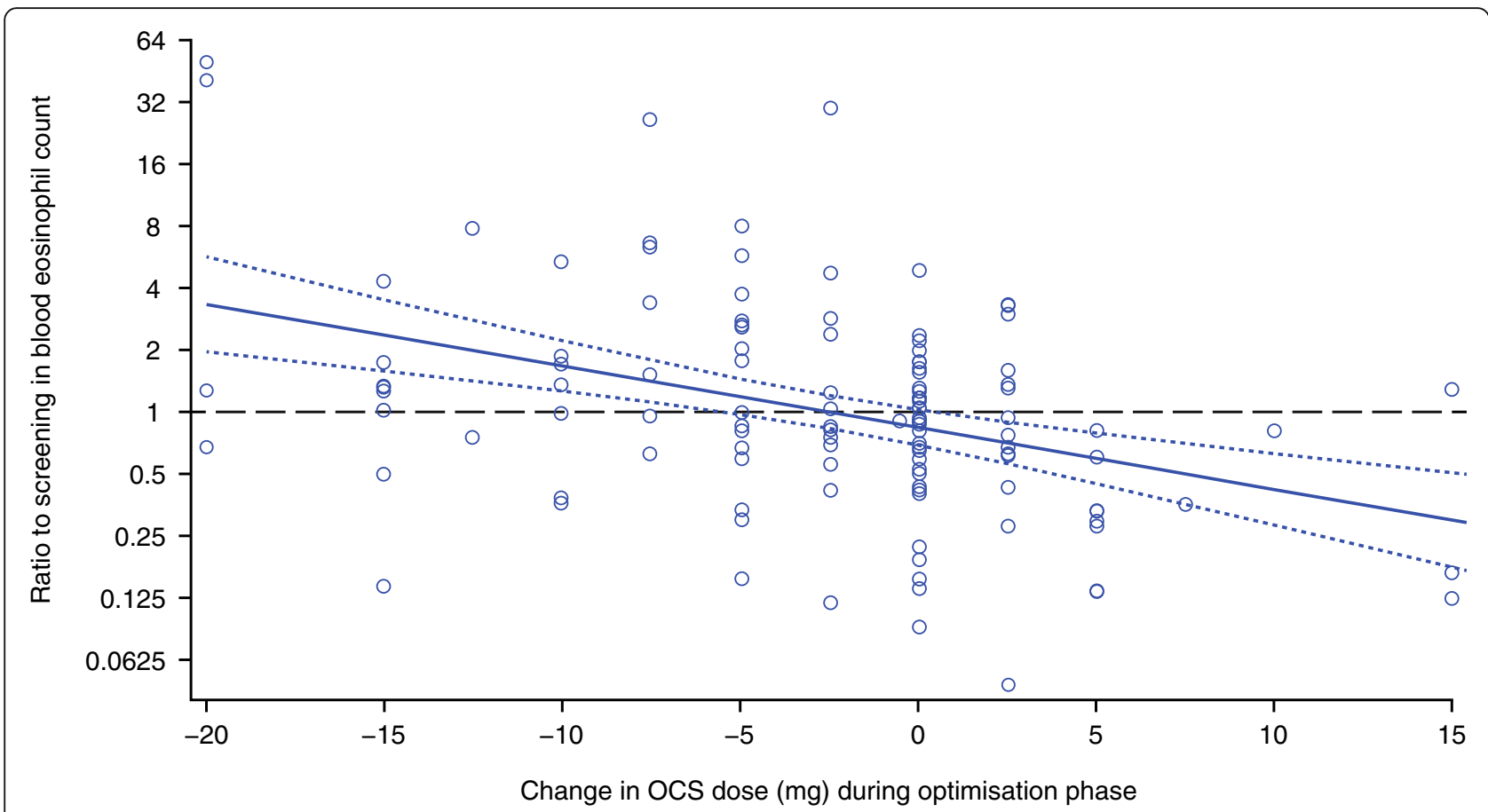

Fig. 1 Linear regression of relationship between change in OCS dose and change in blood eosinophil count. Changes in OCS dose and blood eosinophil counts were measured from the beginning to the end of the optimization phase. A ratio greater than 1 reflects an increase, less than 1 reflects a decrease and 1 reflects no change. Solid and dashed blue lines indicate the mean and 95\% confidence intervals of this relationship, respectively. The black horizontal line represents no change in blood eosinophil count. Circles represent individual patient values. OCS, oral corticosteroid

$5 \mathrm{mg} /$ day reduction in OCS dose resulting in a $41 \%$ increase in PBE count, suggesting that PBE counts are a sensitive marker reflecting changes in OCS dose. These results provide practical guidance to clinicians tapering OCS doses when treating patients with severe eosinophilic asthma.

\section{Additional file}

Additional file 1: Table S1. Post hoc analysis of SIRIUS (demographics and clinical characteristics). (DOC $45 \mathrm{~kb}$ )

\section{Abbreviations}

ACQ-5: asthma control questionnaire-5; OCS: oral corticosteroid;

PBE: peripheral blood eosinophil

\section{Acknowledgements}

Editorial support (in the form of writing assistance, including development of the initial draft, assembling tables and figures, collating authors comments, grammatical editing and referencing) was provided by Natasha Dean, MSC at Fishawack Indicia Ltd., UK, and was funded by GSK.

\section{Funding}

This post hoc analysis and the parent study were funded by GSK (GSK ID: MEA115575; clinicaltrials.gov ID: NCT01691508).

\section{Availability of data and materials}

Anonymized individual participant data and study documents for the original study (SIRIUS) can be requested for further research from www.clinicalstudydatarequest.com.

\section{Authors' contributions}

CMP and EHB contributed to the conception and design of this analysis. EHB was responsible for acquisition of data. All authors contributed to analysis and interpretation of the data, development of the manuscript and approval of the final draft to be submitted.

\section{Ethics approval and consent to participate}

This was a post hoc analysis of the SIRIUS study; the original study protocol was approved by the appropriate investigational center ethics committee or institutional review board in accordance with the International Conference on harmonization of Technical Requirements for Registration of Pharmaceuticals for Human Use (ICH) Good Publication Practice (GPP). All patients provided their consent.

\section{Consent for publication}

Not applicable.

\section{Competing interests}

CMP, RGP, ESB, FCA and SWY are all employees of GSK and hold shares in GSK. EHB reports grants and personal fees from GSK.

\section{Publisher's Note}

Springer Nature remains neutral with regard to jurisdictional claims in published maps and institutional affiliations.

\section{Author details}

${ }^{1}$ Respiratory Medical Franchise, GSK, Research Triangle Park, 5 Moore Drive, PO Box 13398, Raleigh-Durham, North Carolina 27709, USA. ²Department of Respiratory Medicine, Academic Medical Center, University of Amsterdam, Amsterdam, Netherlands. ${ }^{3}$ Clinical Statistics, GSK, Stevenage, Hertfordshire, UK. ${ }^{4}$ Respiratory Therapeutic Area, GSK, Research Triangle Park, Raleigh-Durham, NC, USA. 
Received: 19 December 2018 Accepted: 24 April 2019

Published online: 03 May 2019

\section{References}

1. Yancey SW, Keene ON, Albers FC, Ortega H, Bates S, Bleecker ER, et al. Biomarkers for severe eosinophilic asthma. J Allergy Clin Immunol. 2017; 140(6):1509-18

2. Global initiative for asthma: global strategy for asthma management and prevention. 2018.

3. Daugherty J, Lin X, Baxter R, Suruki R, Bradford E. The impact of long-term systemic glucocorticoid use in severe asthma: a UK retrospective cohort analysis. J Asthma. 2018;55(6):651-8

4. Chung KF, Wenzel SE, Brozek JL, Bush A, Castro M, Sterk PJ, et al. International ERS/ATS guidelines on definition, evaluation and treatment of severe asthma. Eur Respir J. 2014:43(2):343-73.

5. IImarinen $\mathrm{P}$, Kankaanranta $\mathrm{H}$. Eosinophil apoptosis as a therapeutic target in allergic asthma. Basic Clin Pharmacol Toxicol. 2014;114:109-17.

6. Bel EH, Wenzel SE, Thompson PJ, Prazma CM, Keene ON, Yancey SW, et al. Oral glucocorticoid-sparing effect of mepolizumab in eosinophilic asthma. N Engl J Med. 2014;371(13):1189-97.

7. Deykin A, Lazarus SC, Fahy JV, Wechsler ME, Boushey HA, Chinchilli VM, et al. Sputum eosinophil counts predict asthma control after discontinuation of inhaled corticosteroids. J Allergy Clin Immunol. 2005; 115(4):720-7.

8. Leuppi JD, Salome CM, Jenkins CR, Anderson SD, Xuan W, Marks GB, et al. Predictive markers of asthma exacerbations during stepwise dose reduction of inhaled corticosteroids. Am J Respir Crit Care Med. 2001;163:406-12.

9. Ortega H, Katz L, Gunsoy N, Keene O, Yancey S. Blood eosinophil counts predict treatment response in patients with severe eosinophilic asthma. J Allergy Clin Immunol. 2015;136(3):825-6.

Ready to submit your research? Choose BMC and benefit from:

- fast, convenient online submission

- thorough peer review by experienced researchers in your field

- rapid publication on acceptance

- support for research data, including large and complex data types

- gold Open Access which fosters wider collaboration and increased citations

- maximum visibility for your research: over $100 \mathrm{M}$ website views per year

At BMC, research is always in progress.

Learn more biomedcentral.com/submissions 